Journal of

Strategic Management

(JSM)

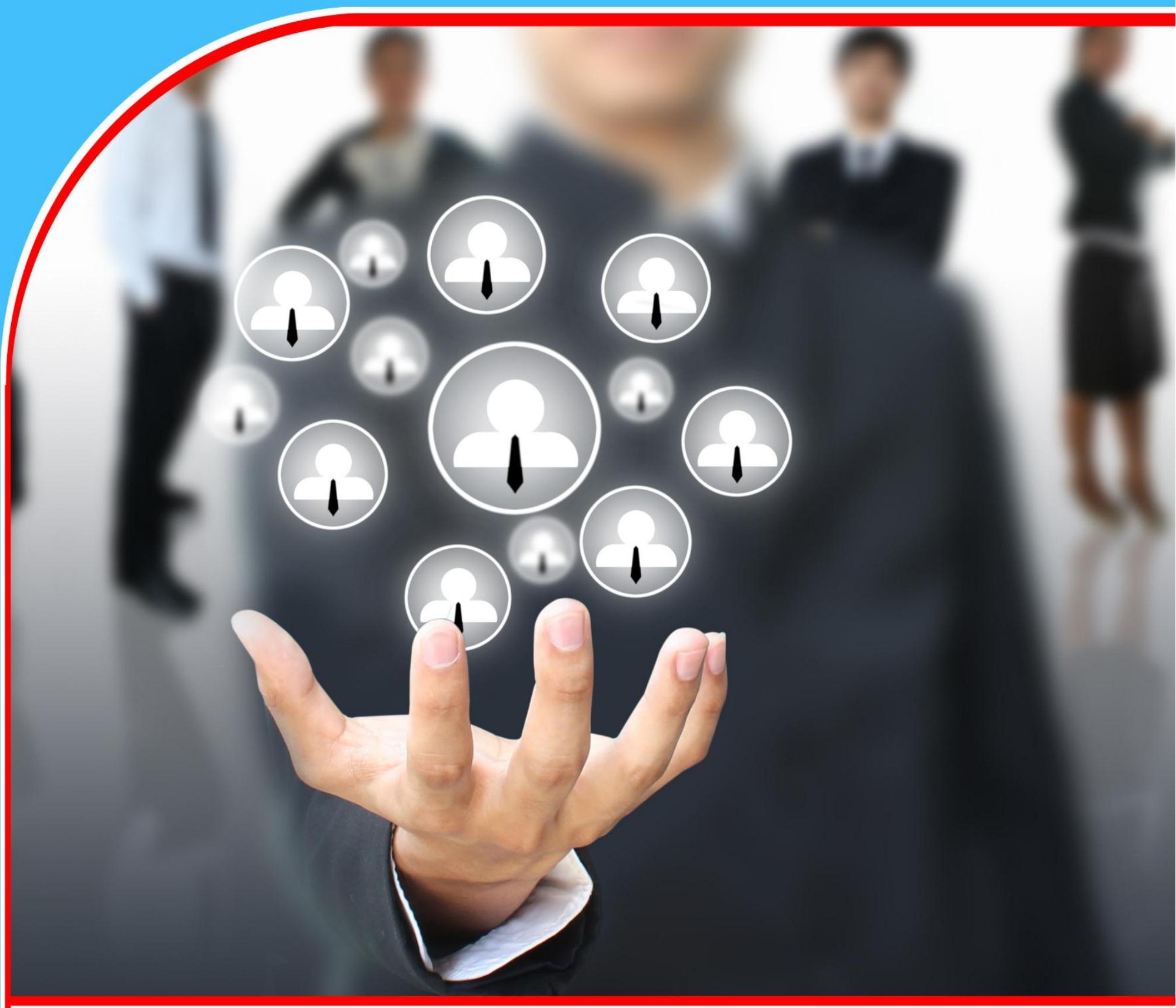

Organizational Change and Strategic Thinking

Kehinde David Folarin

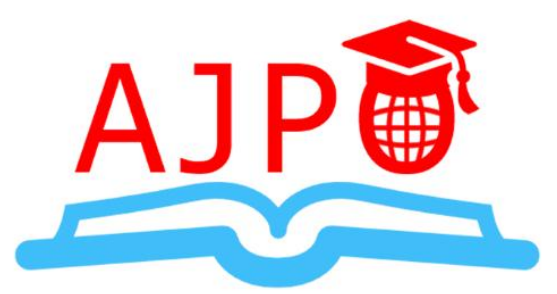




\title{
Organizational Change and Strategic Thinking
}

\author{
Kehinde David Folarin \\ Regent University \\ School of Global Leadership \& Entrepreneurship \\ Email: kehifol@mail.regent.edu
}

\begin{abstract}
In most organizations, the strategic planning process is an annual exercise at best. It ensures that leaders pause at some point to take stock in their organizations, look out over the horizon, assess the external environment and establish their team's priorities and goals. It's a valuable process. However, it doesn't typically happen frequently or fast enough to address the challenges and complexities of the present-day corporate world. That's why leaders with strategic thinking skills have the edge in navigating organizational change. This article addresses the current scenario and realities of organizations and proffered some recommendations.
\end{abstract}

Key Words: Organizations, Strategic Thinking, Change, Organizational Leaders and Change. 


\section{Introduction}

\section{Leading Strategically}

In today's dynamic and confusing global environment, the need for individuals and leaders of all types to become and remain strategic thinkers on a daily basis is a necessity for successful change and business growth and given the dramatic and sometimes tectonic shifts that have characterized the global economy over the last few years, organizations have been forced to reconsider their approach to organizational change. At the same time, the organization has had to continue to deliver value and demonstrate return on efforts, all within the context and constraints of the current market. There is instinctively value and use of strategic planning or thinking regarding retirement, our children's schooling, our vacations, and a multitude of other realities. I want to introduce you to the practice of structured strategic thinking and help you see the value of this practice. The one question that every organization must answer in order not just to survive, but also to realize its true reason for existence is . . "What is our sustainable competitive advantage?"

\section{Strategic Thinking}

Strategic thinking is not an easy concept to distill into one or two concepts simply because authors and researchers cannot seem to agree on a single definition. Probably the most suited for this article is that of Garratt (1995) which states that strategic thinking is a process by which senior executives can rise above the daily managerial responsibilities and crises to gain a different perspective of both the organization and the environment within which the organization is found. Rising above the daily managerial processes and taking a "helicopter view" of the organization enables the leaders within an organization to "hover" above the organization whilst considering a range of possible strategic options. The helicopter can rotate on its own axis which enables the pilot to scan the past and then look to the future with purpose and insight. Often, it is only when leaders are able to see beyond the immediacy of both the urgent and important that they enjoy the fresh perspective of thinking in time (past, present and future). Generating hypotheses of "what if?" and "if then?" By developing more intuitive approaches to strategy alongside the rational, analytical thought processes, strategic thinking provides for a juxtaposing of ideas that can be held in tension.

The ability to think both creatively and opportunistically. Put simply, strategic thinking provides organizational leaders with the ability to look for innovative and imaginative ideas by reconsidering the future and then repositioning the organization within that possible future. This means that the organization will need to then reconsider its core strategies and possibly even its market offering in the context of this future scenario. Birnbaum (2004) says strategic thinking is "concerned with doing the right things, rather than doing things right." This is critical because change is inevitable. As change invades our organization or personal business, we can easily get caught protecting the way we do things, rather than focusing on what we should be doing. Change has a way of knocking us off guard and making us lose our equilibrium. Thinking strategically can help us maintain a healthy balanced posture, directing us to positive outcomes in the face of change. 
When leaders are thinking strategically, they will be;

1. Looking at emerging trends.

2. Identifying whether or not they represent opportunities or threats to their organization or ministry.

3. Developing an organizational response to take advantage of the potential opportunity or mitigate the threat.

\section{Looking at the Emerging Trends}

When looking at needed change and attempting to identify emerging trends that apply or affect our organizations, Switzer (2008) recommends asking questions of stakeholders (employees, consultants, board members, the community). Switzer suggests asking: What trends could impact the organization in the next several years? What are other organizations with similar success factors doing? What potential external threats may impact us/them? The idea of engaging stakeholders in the process is to help create buy-in to the change efforts.

\section{Identifying the Emerging Trends as Threats or Opportunities}

Dutton and Jackson (1987) report that "opportunity" implies a positive situation in which gain is likely and over which one has a fair amount of control. Whereas, "threats" imply a negative situation in which loss is likely and over which one has relatively little control. Though that may be a factual generalization, I would argue that a threat can often become an opportunity when we strategically analyze and address it.

\section{Develop a Response to Take Advantage or Mitigate the Threat}

Through strategic thinking the response to either an identified opportunity or threat is simply calculated change. It is a plan of action that takes into consideration the emerging trend, and the reality of this trend being an opportunity or threat. The result is a strategic response, as opposed to a reflex reaction. As we all know reactions can be emotional and not thoroughly thought through.

In making the case for strategic thinking as a precursor to strategic planning, we now need to turn our attention to organizational change. The real challenge for an organization is to continue to find ways to exploit existing markets whilst exploring new market opportunities (Judge, 2008). This may require a strategic ambidexterity that will combine the need for change with an organization's "ability to combine exploration and exploitation strategies across products, market and resource domains." To support this statement, let's explore the concept of organizational change.

\section{Strategic Thinking - Organizational Change: The Connection}

By examining both strategic thinking and organizational change, all that is required now is to bring the two concepts together and make the link. If we are "in the helicopter" with an overall view of the current state of affairs, we are also able to critically and strategically analyze what is coming. The place where strategic thinking and organizational change best intersect is in the realm of scenario planning. Just as a helicopter pilot runs simulations for most eventualities, even though he is only ever likely to experience a fraction of those scenarios, so a strategic thinker can create scenarios and simulate "what if " situations that enable his organization to more effectively pre-empt or even introduce a desired change. The leap from forecasting to foresight is best made through visualization. Visualization involves 
asking, "What does the next generation look like?" Through visual thinking leaders are able to tap into a creative state that brings the future into the present. By examining not just who they are now, but also who, or what they want to be in the future, leaders who embrace strategic thinking are better equipped to challenge the status quo and anticipate change. According to a McKinsey report, $40 \%$ of firms fail to execute strategy due to lack of capability, another $30 \%$ fail because of lack of readiness for change, and $17 \%$ fail due to poor strategy formulation (Sanders, 1998).

\section{Think Strategically}

Upon reflection, the following were suggested as varieties of approach to think strategically as a leader.

1. Read a variety of literature, inside and outside of your specific discipline

2. Develop "social networks."

3. Attend conferences and/or professional associations.

4. Identify potential threats/opportunities and/or visioning about the future.

5. Use outside consultants, paid and unpaid.

6. Seek information from colleague, employees and other stakeholders.

\section{Conclusion}

This article supports the notion of strategic thinking as an important antecedent activity to organizational change. In a rapidly, dynamic changing environment, leaders require critical thinking skills to move from reactive decision making to proactive foresight. In the midst of the chaos and complexity of the modern world, the effective leader is one who recognizes that, whilst it is impossible to see the future, one can take a perspective that will provide some clues as to what's up ahead. This kind of approach requires leaders to embrace a new planning paradigm that involves taking a step back and seeing the organizations we lead in the context of an open system environment. When we can do this, we will be far better positioned to identify, respond to, and influence the changes impacting on, or required in that environment. Things are changing around us and they are changing quickly. Some people ignore change and that is a problem. Change is inevitable. Things change, whether for good or for bad. When you are a leader, you actually do not wait for change to happen; you make it happen. You initiate change. The ultimate test of leadership is the ability to create change. People naturally resist change. To weaken resistance to change, we must deal with the underlying assumptions and traditions. Once you do that, the resistance to change will be limited. Are you ready to take a ride? 


\section{References}

Birnbaum, B. (2004). Strategic Thinking: A Four-Piece Puzzle. Costa Mesa, California; Douglas Mountain Publishing.

Dutton, Jane E., Jackson, Susan E. (1887). Categorizing Strategic Issues: Links to Organizational Action. Academy of Management Review, 12, no.1:76-90.

Garratt, B. (1995). Introduction in Garratt, B. (Ed.) Developing strategic thought. Rediscovering the art of direction-giving. London: McGraw-Hill.

Hsieh, T. Y., \& Yik, S. (2005). Leadership as the starting point of strategy. McKinsey Report, February, 1-10.

Judge, W. Q. (2008). Organizational capacity for change and strategic ambidexterity. European Journal of Marketing, 42 (9/10), 915-926.

Strategic thinking and the new science. Planning in the midst of chaos, complexity, and change. NY: Simon \& Schuster.

Switzer, M. (2008). "Strategic Thinking in Fast-Growing Organizations.” Journal of Strategic Leadership, 1, no. 1:31-38.

http://www.regent.edu/acad/global/publications/jsl/vol1iss1/JSL_Vol1iss1_Switzer.pd $\underline{\mathrm{f}}$ 